Perspective

\title{
Dry and periparturient cow adaptation to optimized starch assimilation
}

\begin{abstract}
This article describes how proper adaptation to optimized starch assimilation during dry period and through periparturient phase can improve dairy cow production and health. Feeding blends of differently processed grains is a viable strategy. Feeding different grains (e.g., corn and barley) with both soft and hard endosperms is another helpful strategy. Welladapted rumen and post-rumen conditions to adequate starch feeding is a must for healthy and persistent lactation.
\end{abstract}

Keywords: starch, dry cow, assimilation, processing
Volume 7 Issue I - 2017

\author{
Akbar Nikkhah \\ Department of Animal Sciences, University of Zanjan, Iran \\ Correspondence: Akbar Nikkhah, Department of Animal \\ Sciences, Faculty of Agricultural Sciences University of Zanjan, \\ Iran,Email anikkha@yahoo.com
}

Received: July 2I, 20I7 | Published: September 2I, 2017

\section{Introduction}

The objective of this article was to describe how proper adaptation to starch assimilation during dry period and periparturient phase can improve production and health in dairy cows. Starch is a major component in dairy cow rations that requires optimization in both inclusion rate and processing. ${ }^{1-4}$ Although not always wise, it is a common practice to feed up to $35-40 \%$ cereal grains in dairy diets (dry matter basis). This is very risky when highly fermentable grains such as barley and wheat are fed. But, it is not as risky when corn and sorghum are fed because these grains possess harder endosperm (comparing barley and wheat) that is fermented much less rapidly in the rumen. ${ }^{5-8}$

Feeding a combination of soft (e.g., barley and wheat) and hard (e.g., corn and sorghum) grains can improve rumen fermentation and prevent sub acute rumen acidosis (SARA). Implementing this strategy during dry period and especially through periparturient phase (i.e., 3 weeks before and after calving) is very critical. Feeding differently processed grains of mainly ground and dry and steam-rolled grains would be a thoughtful practice that would support healthy rumen fermentation. Rumen microbes require different sources of differently processed starches to stay safe and sound.

To prevent obesity, cows must receive much long forage alongside starchy grains during the dry period. Some farmers greatly limit grain feeding to dairy cows just not to over feed them and indeed to not cause obesity. But, this strategy must be revisited. When and if more than adequate forage fibers are fed, only moderate reductions in grain feeding would suffice. It must be noted that cows should receive adequate amount of starchy grains to remain adapted and perform well after calving when they usually receive high rates of grains in their lactation diet.

Adding slowly degradable grains such as sorghum to dry and periparturient rations can ensure that rumen fermentation stays stable enough with reduced risk from SARA. Forage and concentrate may be fed separately to promote the rumen adaptation to optimal starch assimilation during dry and periparturient periods.

\section{Implication}

This article discussed optimal starch feeding and processing strategies for dry and periparturient dairy cows. This adaptation was for more effective starch assimilation during lactation for superior productivity and health.

\section{Acknowledgements}

None.

\section{Conflict of interest}

The author declares no conflict of interest.

\section{References}

1. Nutrient Requirements of Dairy Cattle. Seventh Revised Edition. USA: The National Academies Press; 2001.

2. Nikkhah A. Moderated Starch Feeding for Sustainable Ruminant Agrotechnology. J Dairy Vet Anim Res. 2016:4(1).

3. Nikkhah A. Improving Dairy Cow Health through Optimizing Starch Nutrition: A Postmodern Perspective. Int J Vet Health Sci Res. 2016;4(2):86-87.

4. Nikkhah A. Cereals and Periparturient Ruminants. J Veterinar Sci Technol. 2015;6:6.

5. Nikkhah A. Multisource Starch for Optimal Rumen and Ruminant Integrity. $J$ Adv Dairy Res. 2015;3:4.

6. Nikkhah A. Optimizing Starch Nutrition for Postmodern Ruminants: Science against Pseudoscience. J Adv Dairy. 2015;3:4.

7. Nikkhah A. Delicate Artistic Cereal Provision to Reduce Negative Nutrient Balance and Improve Dairy Cow Health. J Adv Dairy. 2015;3:4.

8. Nikkhah A. The Art of Manipulating Nutrient Bioprocessing In Ruminants: Behind the Rumen Wheel. $J$ Bioprocess Biotech. 2015;5:e134. 